\title{
Regulation of Calcitonin Secretion in Normal Man by Changes of Serum Calcium within the Physiologic Range
}

\author{
Lynn A. Austin, Hunter Heath III, and Vay Liang W. Go, Mayo Medical School, \\ the Endocrine Research Unit, and the Gastroenterology Unit, Department of \\ Medicine, Mayo Clinic, Rochester, Minnesota 55901
}

\begin{abstract}
A B S T RACT To examine the relative importance of calcium and gastrin in regulation of calcitonin secretion, we administered graded oral doses of calcium to 10 normal men, ages 23-29 yr. Each subject had previously shown an appropriate increase in calcitonin secretion in response to a pharmacologic $(0.5 \mu \mathrm{g} / \mathrm{kg})$ pentagastrin injection. On separate days and in random order, each man drank $250 \mathrm{ml}$ of distilled water containing $0.0,0.5,1.5$, and $3.0 \mathrm{~g}$ of elemental calcium as the gluconate salt. Blood samples were drawn before and at $30,60,90,120,180$, and $240 \mathrm{~min}$ after the oral calcium dose. The samples were analyzed for calcium by atomic absorption spectroscopy, and for gastrin and calcitonin by radioimmunoassays of established sensitivity and specificity. Ingestion of water (control) caused no change in any of the three variables. Calcium ingestion resulted in dose-related increases, within the normal range, of all three variables. Immunoreactive gastrin rose promptly, peaking at $30 \mathrm{~min}$, and returning to basal levels or below by $120 \mathrm{~min}$. In contrast, calcium and immunoreactive calcitonin levels rose slowly and in parallel, peaking at 120-240 min. Changes in calcitonin and changes in calcium were strongly and positively correlated, $r=0.73$, when all data were pooled. Furthermore, individual linear regressions for changes in calcitonin and calcium levels (calculated separately for the three oral calcium doses in each subject) had positive slopes in 28 out of 30 sets $(P<0.01)$. The changes in calcitonin concentrations were much more poorly correlated with the corresponding changes in serum gastrin levels; in fact, the regression coefficient was weakly negative, $r=-0.20$. These results show that, at least in young adult men, changes of ambient calcium concentration within the normal range may be of
\end{abstract}

Address reprint requests to Dr. Heath.

Received for publication 3 August 1979 and in revised form 10 September 1979. major importance in physiologic regulation of calcitonin secretion. The findings are consistent with the hypothesis that calcitonin functions to prevent excessive postprandial hypercalcemia.

\section{INTRODUCTION}

Pharmacologic doses of calcium and gastrin are known to be calcitonin $(\mathrm{CT})^{1}$ secretagogues in normal man (1), and animal studies $(2,3)$ suggest that gastrin might be a major physiologic regulator of CT secretion. However, a recent study from this laboratory (4) showed that mixed meals, which markedly stimulated gastrin secretion but did not raise serum calcium levels, had no effect on plasma immunoreactive CT (iCT) concentrations in normal men. These results suggest that the gastrin-CT interaction observed in animals, and in patients with the Zollinger-Ellison syndrome (5), may have little or no physiologic significance in normal adult men. Questions have also been raised as to whether physiologic changes of $\mathrm{Ca}$ are of importance to CT secretion, because most investigators have been unable to detect increases of iCT after oral Ca feeding in $\operatorname{man}(6,7)$.

The present study further examines the relative importance of calcium and gastrin in the regulation of CT secretion. We measured the changes in peripheral blood levels of $\mathrm{Ca}$, serum immunoreactive gastrin (iG), and iCT after $\mathrm{Ca}$ ingestion in 10 healthy young men. The results show that, in young men, increases of $\mathrm{iCT}$ are strongly correlated wth changes in serum Ca levels, but not with the changes in iG levels. These findings suggest the hypothesis that $\mathrm{Ca}$ is a major physiologic regulator of $\mathrm{CT}$ secretion in normal men.

\footnotetext{
${ }^{1}$ Abbreviations used in this paper: CT, calcitonin; iCT, plasma immunoreactive CT; iG, serum immunoreactive gastrin.
} 


\section{METHODS}

The paid volunteers were all males between the ages of 23 and $29 \mathrm{yr}$ and were selected from a group of 20 Mayo Medical School students. They had all had a recent normal health examination at the Mayo Clinic and were taking no medications. All subjects gave informed consent to the studies, which were performed in the Clinical Research Unit at St. Mary's Hospital. After an overnight fast, each volunteer was given a single bolus intravenous pentagastrin injection, $0.5 \mu \mathrm{g} / \mathrm{kg}$ in $0.9 \% \mathrm{NaCl}$ (Peptavlon, Ayerst Laboratories, New York). Of the 20 students screened, all 20 had basal iCT levels that were detectable in our assay, and all but 5 showed a significant increase in iCT levels 2 min after the pentagastrin injection. From this group, we selected the 10 men who showed the greatest absolute increase in iCT. For this study group, the mean basal iCT \pm SD was $31 \pm 12 \mathrm{pg} / \mathrm{ml}$ (range, 20-63 $\mathrm{pg} / \mathrm{ml}$ ), and the mean value after injection was $71 \pm 20 \mathrm{pg} / \mathrm{ml}$ (range, 43-111 pg/ml).

\section{Oral calcium studies}

All studies began after an overnight fast and before 0900 . The subjects stayed recumbent during the study period. Blood was drawn from an indwelling venous catheter placed in the forearm of each subject at least 20 min before the first sample. In random order and on separate days (at least $5 \mathrm{~d}$ apart), each subject was given orally, $250 \mathrm{ml}$ of distilled water containing $0.0,0.5,1.5$, and $3.0 \mathrm{~g} \mathrm{Ca}$ as the gluconate salt. Blood samples were drawn before and at $30,60,90,120,180$, and 240 min after $\mathrm{Ca}$ ingestion. Blood samples were kept on ice during the study period, and plasma or serum separated from the cells at the end of each study. Samples were then stored at $-20^{\circ} \mathrm{C}$ for no more than $6 \mathrm{wk}$ before analysis.

\section{Analytical methods}

Plasma immunoreactive calcitonin. We measured iCT by the method of Heath and Sizemore (1), which has been described in detail. Briefly, antiserum G1701 (goat anti-human CT), used at a final dilution of $1: 40,000$ has major immunochemical specificity for the amino acid sequence region 11-28 of human CT monomer (1). Synthetic human CT (Ciba-Geigy Corp., Summit, N. J.) was used for standard and tracer ( $\left.{ }^{131} \mathrm{I}\right)$. The limit of detection for these assays averaged $20 \mathrm{pg} / \mathrm{ml}$ of plasma; inter- and intra-assay coefficients of variation for the plasma internal reference standard were $<5 \%$. All samples from each subject were assayed together, and no iCT values fell below the detection limit.

Serum iG. We measured iG by a previously described radioimmunoassay (5) using rabbit anti-human G-17 gastrin serum 3439 (4) at a final dilution of $1: 150,000$. All samples from each subject were assayed together; inter- and intra-assay coefficients of variation were $<10 \%$ for these studies.

Serum $\mathrm{Ca}$. Serum Ca was measured by atomic absorption spectroscopy (Perkin-Elmer Corp., Norwalk, Conn.) (8), normal adult range, $8.9-10.1 \mathrm{mg} / \mathrm{dl}$.

Statistical analyses. Data were analyzed by a variety of techniques, including $t$ test, signed rank test, and least-squares linear regression (9). Because of the relatively small sample size, our statistical consultant regarded multivariate analyses as inappropriate for these data.

\section{RESULTS}

The results of this study are summarized in Fig. 1, which shows mean changes in $\mathrm{Ca}, \mathrm{iCT}$, and $\mathrm{iG}$ for all

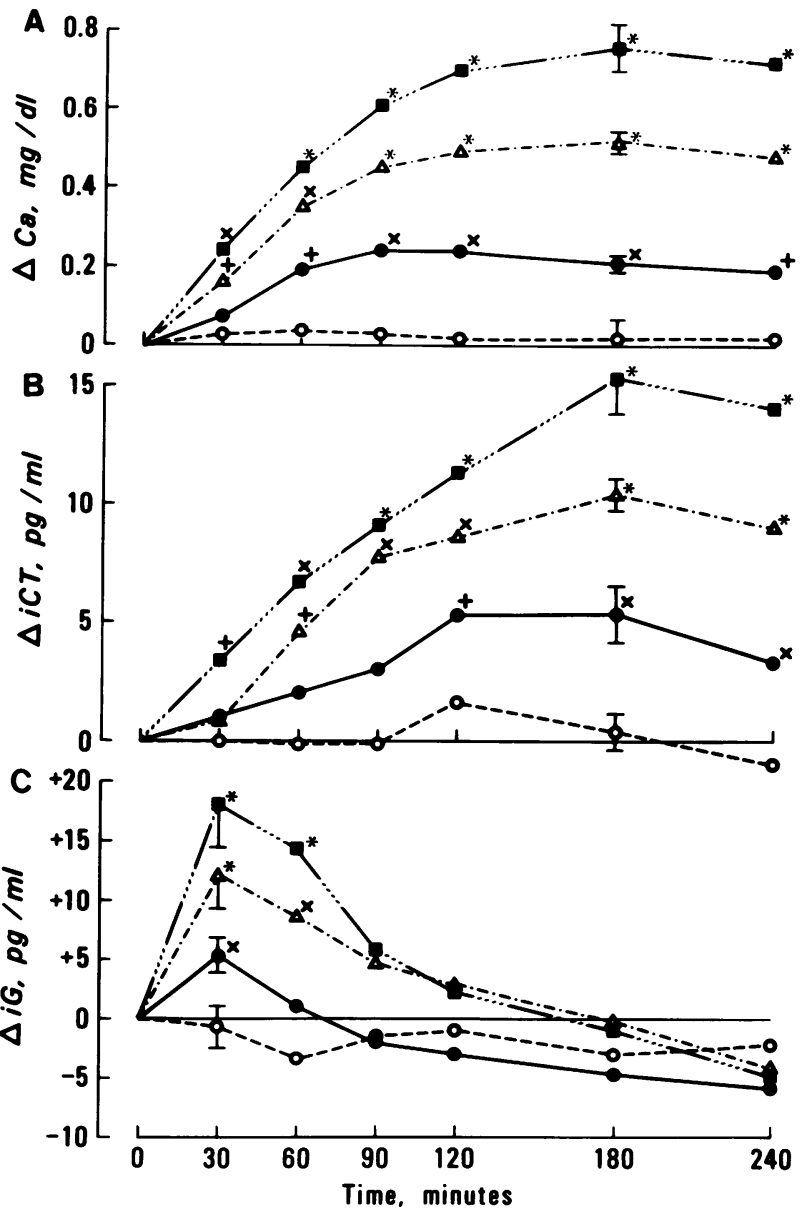

FIGURE 1 Effects of oral calcium ingestion in normal men. Mean changes in serum $\mathrm{Ca},(\Delta \mathrm{Ca}, \mathrm{A})$, iCT $(\Delta \mathrm{iCT}, \mathrm{B})$, and iG $(\Delta \mathrm{iG}, \mathrm{C})$ are plotted vs. time after ingestion of $0.0 \mathrm{~g}(\mathrm{O}), 0.5 \mathrm{~g}$ $(\odot), 1.5 \mathrm{~g}(\Delta)$, and $3.0 \mathrm{~g} \mathrm{Ca}(\square)$ in 10 normal male volunteers. Statistically significant differences from corresponding control values are indicated by:,$+ P<0.05 ; \times, P<0.01 ; *, P<0.001$. Standard errors of the mean are shown at representative points.

10 subjects during the $4 \mathrm{~h}$ after water or Ca ingestion. Ingestion of water (control) caused no change in any of the measured variables. In contrast, after $\mathrm{Ca}$ ingestion, there were significant, dose-related increases of mean Ca levels, which reached a maximum at $2-3 \mathrm{~h}$. It is important to note that these increases remained within the physiologic range in 9 out of 10 of the subjects studied, with the maximum $\mathrm{Ca}$ observed in the 10th subject being only $10.2 \mathrm{mg} / \mathrm{dl}$. There were consistent, dose-related, and statistically significant increases in mean iCT levels, which closely paralleled the time-course of changes in $\mathrm{Ca}$, also reaching a maximum at 2-3 h. Calcium ingestion also produced modest, but statistically significant increases of endogenous iG levels. However, these small changes in $\mathrm{iG}$ were maximal at $30 \mathrm{~min}$ and had returned to or below basal levels 


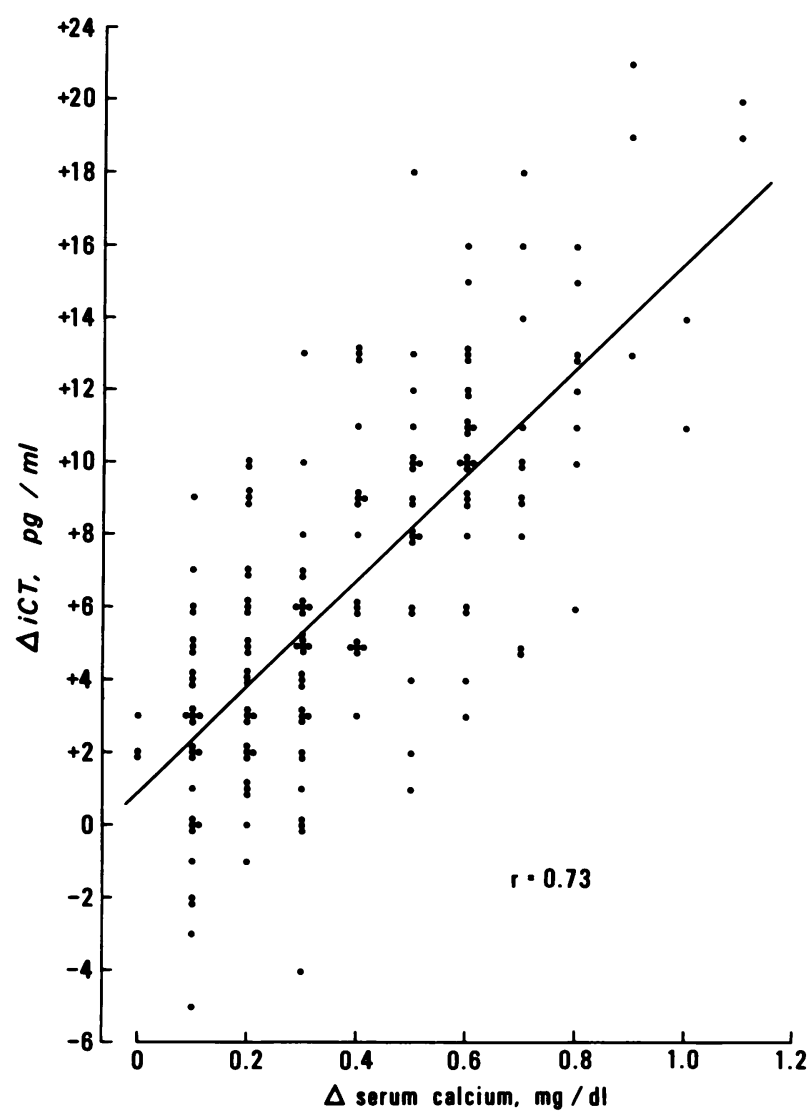

FIGURE 2 Changes in $\mathrm{iCT}(\Delta \mathrm{iCT})$ plotted vs. the corresponding changes in serum $\mathrm{Ca}$ after $\mathrm{Ca}$ ingestion. The data represent the responses of all 10 subjects to each of the three oral $\mathrm{Ca}$ doses at all time intervals studied. The linear regression was calculated by the method of least squares.

by $180 \mathrm{~min}$, when $\mathrm{iCT}$ and Ca concentrations were greatest.

It is apparent from Fig. 1 that the observed changes in $\mathrm{CCT}$ were more closely correlated with the changes of serum Ca levels than with the corresponding changes in $\mathrm{iG}$ concentrations. This impression is confirmed by pooling the data and analyzing $\triangle \mathrm{iCT}$ as a function of $\Delta \mathrm{Ca}$ (Fig. 2). Regression analysis yielded a regression coefficient of +0.73 . Furthermore, when the individual responses of each subject to each of the three Ca doses were analyzed separately, 28 out of 30 sets showed a positive correlation between $\triangle \mathrm{iCT}$ and $\triangle \mathrm{Ca}$. These relationships were significant for all three $\mathrm{Ca}$ doses by the signed rank test $(0.5 \mathrm{~g} \mathrm{Ca}, P<0.05 ; 1.5$ and $3.0 \mathrm{~g}$ $\mathrm{Ca}, P<0.01)$. In contrast, the correlations between $\Delta \mathrm{iCT}$ and $\Delta \mathrm{iG}$ were weakly negative in the pooled data as well as individually in 30 out of 30 cases.

\section{DISCUSSION}

In pharmacologic doses pentagastrin is a well-known CT secretagogue (1-4), and many studies suggest that endogenous gastrin levels could play a major role in regulating CT secretion $(5,10)$. We have demonstrated that in normal young men, ingestion of Ca resulted in dose-related increases of circulating $\mathrm{Ca}$, iG, and iCT concentrations. However, the iCT changes were positively correlated both in time and magnitude with the corresponding changes of serum $\mathrm{Ca}$, not iG levels. A possible interpretation of these data is that the early increase of iG levels caused a prolonged increase of CT secretion, which fortuitously paralleled the slow rise in serum Ca concentration. However, Owyang et al. (4) showed that pharmacologic doses of pentagastrin caused prompt increases in iCT levels, which returned to basal levels as rapidly as did immunoreactive pentagastrin concentrations. Furthermore, they observed that test meals, which did not change serum $\mathrm{Ca}$ but did result in large, prolonged increases of endogenous gastrin levels (about fivefold greater than in our study), were not associated with detectable increases in iCT. It remains possible that even the small changes we saw in endogenous gastrin play a role in regulation of CT secretion by somehow sensitizing the $\mathrm{C}$ cells to changes in ambient $\mathrm{Ca}$ concentrations. However, we are not aware of experimental evidence to directly support this hypothesis.

Our data show that, in healthy young men, changes of $\mathrm{Ca}$ concentrations within the physiologic range are associated with parallel changes of iCT levels. In contrast, Ca-induced rises of iG could not be correlated in time or magnitude with changes of iCT. We believe a conservative interpretation of these and other data $(1,4)$ is that in normal men, ambient $\mathrm{Ca}$ is a major regulator of $C T$ secretion. While we suspect that the findings described here are applicable to women as well as men, the lower iCT in female subjects (1) makes this difficult to verify. The relative CT deficiency seen in women may also explain why other investigators $(6,7)$ have not regularly found increased iCT after oral Ca. In any case, the results are consistent with the hypothesis that CT functions to prevent excessive postprandial hypercalcemia in man (10-13).

\section{ACKNOWLEDGMENTS}

We are grateful for the expert technical assistance of Sandra Stokes, Joan Larson, Deanna Nash, Karen Laakso, and Sandy Michener; and the excellent manuscript preparation of Marylee Fair and Cheryl Collins.

This work was supported by grants from the National Institutes of Health (AM-19607, AM-21101, RR-585, and AM0718), Mayo Medical School, and The Mayo Foundation.

\section{REFERENCES}

1. Heath, H., III, and G. W. Sizemore. 1977. Plasma calcitonin in normal man. J. Clin. Invest. 60: 1135-1140.

2. Cooper, C. W., W. H. Schwesinger, A. M. Mahgoub, and D. A. Ontjes. 1971. Thyrocalcitonin: stimulation of se- 
cretion by pentagastrin. Science (Wash. D. C.). 172: 1238-1240.

3. Care, A. D., R. F. L. Bates, R. Swaminathan, and P. G. Ganguli. 1971. The role of gastrin as a calcitonin secretagogue. J. Endocrinol. 51: 735-744.

4. Owyang, C., H. Heath, III, G. W. Sizemore, and V. L. W. Go. 1978. Comparison of the effects of pentagastrin and meal-stimulated gastrin on plasma calcitonin in normal man. Am. J. Dig. Dis. 23: 1084-1088.

5. Sizemore, G. W., V. L. W. Go, E. L. Kaplan, L. J. Sanzenbacher, K. H. Holtermuller, and C. D. Arnaud. 1973. Relations of calcitonin and gastrin in the Zollinger-Ellison syndrome and medullary carcinoma of the thyroid. $N$. Engl. J. Med. 288: 641-644.

6. Heynen, G., and P. Franchimont. 1974. Human calcitonin radioimmunoassay in normal and pathological conditions. Eur. J. Clin. Invest. 4: 213-222.

7. Parthemore, J. G., and L. J. Deftos. 1978. Calcitonin secretion in normal human subjects. J. Clin. Endocrinol. Metab. 47: 185-188.
8. Slavin, W. 1968. Atomic Absorption Spectroscopy. WileyInterscience Div., John Wiley \& Sons, Inc., New York.

9. Dixon, W. J., and F. J. Massey, Jr. 1969. Introduction to Statistical Analysis. McGraw-Hill Book Co., New York. 3rd edition.

10. Munson, P. L. 1976. Physiology and pharmacology of thyrocalcitonin. In Handbook of Physiology. Vol. VII, Endocrinology. G. D. Aurbach, editor. Waverly Press Inc., Baltimore, Md. 443-464.

11. Gray, T. K., and P. L. Munson. 1969. Thyrocalcitonin: evidence for physiologic function. Science (Wash. D. C.). 166: 512-513.

12. Cooper, C. W., P. F. Hirsch, and P. L. Munson. 1970. Importance of endogenous thyrocalcitonin for protection against hypercalcemia in the rat. Endocrinology. 86: 406-415.

13. Coen, G., and B. Palagi. 1975. Blood calcium homeostasis during intestinal calcium absorption in man. Rendiconti di Gastroenterologia. 7: 173-176. 